\title{
Analysis of two degree levels in terms of post-university employability
}

\author{
Daniele TONINELLI, VŠB-Technical University of Ostrava \& University of Bergamo, ${ }^{\mathrm{i}, \mathrm{ii}}$ \\ Silvia BIFFIGNANDI, University of Bergamo ${ }^{\text {ii }}$
}

\begin{abstract}
Recently two levels of graduate degree have been introduced in the Italian University system. This study identifies the key factors underlying postgraduate employability. A comparison of the two degree levels, together with the main profiles of the two groups of graduates, is provided. Segmentation analysis (the CHAID algorithm) is applied to the 2009 population of graduates surveyed so as to profile graduates and identify employability factors. The findings could potentially support a decision-making perspective: they underline important factors that ease the entrance of graduates into the working environment.
\end{abstract}

\section{Keywords}

Employability, graduate survey, graduation levels, CHAID, segmentation analysis.

JEL Classification: I21, C19, C38, J24

\footnotetext{
${ }^{\mathrm{i}}$ Department of Finance, Faculty of Economics, VŠB-Technical University of Ostrava, Sokolská 33, 70121 Ostrava, Czech Republic.

ii Department of Management, Economics and Quantitative Methods, University of Bergamo, via dei Caniana 2, 24127, Bergamo, Italy.

daniele.toninelli@unibg.it (corresponding author)

This paper has been elaborated in the framework of the project Opportunity for young researchers, reg. no. CZ.1.07/2.3.00/30.0016, supported by Operational Programme Education for Competitiveness and co-financed by the European Social Fund and the state budget of the Czech Republic. The paper has been also supported by the $60 \%$ university funds (University of Bergamo). CILEA consortium, given the approval of the involved universities, kindly provided the survey database. We also would like to thank the anonymous referees of the journal, whose helped improving our paper with their useful and interesting suggestions.
}

\section{Introduction}

The Italian government recently re-organized the university system introducing two levels of graduation, known also as the $3+2{ }^{1}$ The first level of gradua-

\footnotetext{
${ }^{1}$ The $3+2$ university reform was introduced by the Ministerial Decree no. 509 of November $3^{\text {rd }}, 1999$. The Medicine disciplinary group was excluded from this transformation: it is currently organized, as in the past, with a single level of graduation corresponding to a 6-year university course. At Bachelor level, the Medicine group is a professional study;
}

tion is called the Laurea Triennale; this is a Bachelorlevel programme ${ }^{2}(B D$, i.e. Bachelor Degree, from this disciplinary group is included in our bachelor-level
analyses.
2 Source: Bologna Process (2009). The Bologna Process
aims at creating the European Higher Education Area
$(E H E A)$, encouraging cooperation between international
organizations and ministries, higher education institutions,
students and staff from 47 countries (For further infor-
mation, see: http://www.ond.vlaanderen.be/hogeronder
wijs/bologna/about/index.htm
http://www.cimea.it/default.aspx?IDC=18). 
here on) and it allows students to obtain a degree ( $B D$ or first level degree) after a 3-year university course, corresponding to 180 ECTS. $^{3}$ Since the BD curriculum represents the basic level of academic degree in Italy, first-level graduates can decide either to end their studies and enter the labour market, or to undertake a higher-level university course. This higher level lasts two years and it is called the Laurea Specialistica, that is, a Master-level Degree $(M D){ }^{4}$ A cumulative amount of 300 ECTS are requested to obtain a MD, which means 120 ECTS during the two master level years. At the conclusion of this second level, students become MD graduates.

The main purpose of the changes introduced by the reform was to encourage the employability of graduates, giving them the possibility to choose to end studies (entering into the labour market) after the first three years of a course or to continue with the following two years of advanced studies.

In a knowledge-based economy, post-graduate employability is a key driving force. Employability is a multi-faceted concept and a complex one. It can be studied using a qualitative method as well as a quantitative one, an absolute as well as a relative measurement. Moreover, it can be approached on the basis of individual skills, of cultural perspective, and so on. Employability relies on the ability of a person to get a job and hold it over a period of time (Hillage and Pollard, 1998; Brown and Hesketh, 2004). In terms of individuals, employability is affected by their own particular skills and education (Employability is having a set of skills, knowledge, understanding and personal attributes that make a person more likely to choose and secure occupations in which they can be satisfied and successful, Dacre Pool and Sewell, 2007a), as well as by many other factors related to the economic scenario rather than individual specificity (Hind and Moss, 2011). Due to the potential com-

\footnotetext{
${ }^{3}$ The European Credit Transfer and Accumulation System (ECTS) is a standard to compare the study attainment and performance of students of higher education across the European Union. It is based on a credit system, a systematic way of describing an educational programme by attaching credits to its components (source: Office for Official Publications of the European Communities, 2004). The definition of credits is based on the student workload required to achieve the objectives of a programme. These objectives are evaluated in terms of the learning outcomes and competences to be acquired using different parameters, such as student workload, learning outcomes and contact hours. 60 ECTS-credits are generally equivalent to 1500 1800 hours of study and usually correspond to one academic year. For further information, see the Office for Official Publications of the European Communities (2004).

${ }^{4}$ Source: Bologna Process (2009).
}

plexity of the employability issue, some choices have to be made and a specific perspective has to be used.

With regard to a definition of employability, a qualitative approach relies on the ability of people to find and keep a job, whereas a quantitative approach considers the probability of a graduate finding employment. Alternative measurement criteria can be used in the quantitative approach, i.e.:

1. The probability of finding employment within a year;

2. The probability of finding permanent employment within a year;

3. The expected percentage of employment time for the year following the survey;

4. The probability of being employed 12 months from the date of the survey.

Employability was studied in different papers (e.g., see Teichler, 2007). Some further studies about employability of graduates in the Euro area could be found, for example, in Schomburg and Teichler (2006, 2011).

Our paper is based on a survey that aims at measuring employability by means of the criterion given in point 1; that is to say, the percentage of graduates employed one year after graduation.

In this framework, it becomes extremely important to understand whether, and how, the university can ease the entrance of graduates into the labour market and which factors determine a higher probability of being employed after graduation (about the transition from school or university to work, see also Brauns et al., 1999, Biggeri et al., 2001, Betts et al., 2000, Couppié and Mansuy, 2003, Eurostat, 2003, Fabbris, 2006, Quintini et al., 2007, Wolbers, 2007, and Garrouste and Loi, 2011). Moreover, following the recent reform, the Italian Ministry of Education, Universities and Research (MIUR) requests, by law, the monitoring of the employability of graduates at both levels of graduation so as to understand the adequacy and coherency of university activities and of the reform itself in relationship to labour market requirements and opportunities provided by it (for further information about the employability of graduates in Italy, see also: Chiandotto and Bertacchini, 2003; the effects of the reform were also studied in Bini and Chiandotto, 2003).

In this paper, we focus mainly on a comparison of the two levels of graduation (Bachelor and Master, that is, BD and MD). This topic is also faced in Luzzatto et al., 2012. More particularly, we investigate factors affecting post-graduate employability among variables describing university studies, experiences and activities, and basic socio-economic graduate characteristics (other results about the Italian university system performances can be found, for example, in 
Biggeri and Bini, 2003). Moreover, in our research we seek to profile graduates according to employability and to determine the traits and factors that facilitate the possibility of having a job one year following both levels of graduation.

To achieve research objectives, we based the analysis of our survey data on the application of segmentation analysis (the CHAID algorithm). This is devoted to profiling graduates according to employment performance.

The following Section 2 describes the details of the methodology used in our study. In Section 3, the survey, the dataset and the target variables of our analysis (§ 3.1) will be briefly introduced.

In Section 4, the main results of the segmentation procedure will be discussed, with reference to different alternative sets of variables. The main objective of this section will be to study and compare the employability of both BD and MD graduates, focusing, in particular, on groups of graduates that have entered the labour market.

In Section 5 the main findings are summarized and some conclusions and directions of research for further exploration will be proposed.

\section{Methodology: the CHAID algoritm}

One of the aim of this paper is to profile and compare, in terms of rate of employability and of their characteristics, the two groups of BD and MD graduates. To carry out an in-depth analysis of the profiles of the abovementioned graduate groups, our study is based on the application of segmentation analysis (these techniques were already used in education studies, e.g. by Spiro, 1978). In particular, we use the CHAID (CHi-squared Automatic Interaction Detection) algorithm, a recursive partitioning method originally proposed by Kass $\left(1980^{5}\right)$ and currently very popular in marketing research: it is used especially in the context of market segmentation studies, mainly as an effective tree-based model useful for predictions. CHAID is also frequently used as an exploratory method (Tukey, 1977), and it is considered an alternative to the multiple regression model, or a method for interpreting a logistic regression model (Ratner, 2011). The algorithm has been also already used, in the higher education sector, for the segmentation of students, chiefly in evaluating their performances (e.g., see Ramaswami and Bhaskaran, 2010), or in

\footnotetext{
5 According to Ripley (1996), the CHAID algorithm was derived from the THeta Automatic Interaction Detection (THAID) method, developed by Morgan and Messenger (1973).
}

describing the characteristics of potential high performers (see Kusakci, 2010).

CHAID is basically an automatic procedure for detecting interactions among variables based on a chisquare test statistic. It could be considered a tree method, which is a method strictly related to classical cluster analysis (Hartigan, 1975). The CHAID algorithm has proven to be an effective approach in obtaining a quick but meaningful segmentation (see, e.g., Antipov, 2010, Hoare, 2004, and Magidson, 1994), where segments can be defined in terms of demographic or other variables that are predictive of a single criterion (dependent) variable.

The CHAID algorithm serves a double purpose. On the one hand, it helps in recoding, on the other hand, it allows for the identification of homogeneous groups. The first step of the CHAID approach allows the variables' classes to be reclassified into a meaningful and potentially reduced number, collapsing the couples of classes that are independent with respect to the criterion variable. ${ }^{6}$ In our case, the algorithm is useful in segmentation with respect to the employability criterion variable (the Work variable). When the tests for each pair of a predictor's categories are all significant, then the algorithm computes a Bonferroni adjusted $p$-value for the set of categories obtained for this predictor and the reclassifying phase finishes. These first recursive steps of the analysis permit us to obtain an optimal reclassification of the variables' classes.

Following this step, the second phase of the CHAID algorithm is implemented and the most significant potential segmentation variables are selected. Significance is evaluated according to the ability to identify the most homogeneous groups of respondents with respect to the criterion variable. Thus, with reference to this variable, the algorithm selects the segmentation variable that identifies the groups with the minimum variance within groups and the maximum variance between groups. In practice, the predictor variable with the smallest adjusted Bonferroni $p$ value is chosen to separate the original groups of units (i.e., the predictor variable that will provide the most significant split is selected). Thus, using the classes of the variable initially chosen (recoded, if convenient), the original group of respondents is divided into two or more groups. After the first step of segmentation, the iterative process continues, identifying two or more sub-groups of homogeneous respondents using, within the remaining segmentation variables, the one

\footnotetext{
${ }^{6}$ Since our dependent variable is categorical, and given that we are dealing with the classification of a group of units, we compute a Pearson Chi-square test (with $\alpha=0.05$ ).
} 
that maximizes the homogeneity of the obtained groups.

Due to the algorithm traits, the variables are selected in a decreasing order of importance: the most discriminant variables in the segmentation process are chosen first. This aspect is important in our research, since we can detect the most important variables in defining homogenous groups of units with reference to the criterion variable (and, consequently, to the employability rate of graduates).

Moreover, these variables also allow us to describe the identified groups reading the results shown in the classification tree. The classification tree (or decision tree) is one of the outputs of the segmentation procedure that we focus on: it describes in details the entire segmentation algorithm. It is mainly made of nodes connected by branches: the original group of units is defined root (or original node); the groups obtained by dividing the root and the following sub-groups obtained during the segmentation procedure are called nodes (or internal nodes). The terminal nodes of the tree (also called leaves) are the groups not further divided, where the segmentation procedure stops. In our analysis we are mainly interested in a description of the main nodes and terminal nodes, chiefly in terms of employability rate.

A segmentation procedure may continue until we obtain terminal nodes made up of one unit only (or until the available segmentation variables finish). Thus, some stopping rules can be chosen to select a more meaningful number of groups. ${ }^{7}$ The segmentation process continues until at least one stopping rule is verified. The main stopping rules are usually based on the computation of a test statistic (chi-square, $F$, etc.): the procedure ceases splitting any node that fails to meet the test. When the smallest Bonferroniadjusted $p$-value for any available predictor is greater than a predefine value of alpha $^{8}$, for each node obtained through segmentation, no further splits are performed and the node in question is considered a terminal node. ${ }^{9}$

Apart from this more general stopping rule, we also establish the following stopping rules in our work with reference to the number of units of the identified groups: the CHAID stops segmenting a group (or a sub-group) of respondents when a parent node (the group to be split) has less than 60 units, or when the number of units belonging to a child node (one of the

\footnotetext{
${ }^{7}$ For further information on the risk of obtaining a tree with too many branches, see Breiman et al. (1984).

${ }^{8}$ In our case, we set $\alpha=0.05$.

${ }^{9}$ For further information on the stopping rules in forward selection regression, see Wilkinson (1979).
}

groups obtained by the segmentation procedure) is smaller than 30 units.

The main findings of segmentation analysis are discussed below in Section 4. In this section, the results obtained for BD and MD graduates are compared in order to highlight potential differences in the selected variables and/or in the strength of their link with employability.

\section{Data source}

The database used in our analysis is the survey on Post Graduate Employment which is part of the framework of STELLA studies (Statistics studies on graduates and the labour market $\left.{ }^{10}\right)$. The interviews took place 12 months after graduation using a sample of 2009 graduates. The survey involved 19,864 graduates (graduating in 2009) from several Universities in Lombardy: Bergamo, Brescia, Milano Statale, MilanoBicocca, and Pavia. A stratified sample (stratification variable: a discipline group from each University) has been extracted for the survey from our dataset. For small strata the whole set of 2009 graduates have been included. The sample is representative of a total population of 29,387 graduates.

The total population can be broken down by graduation level as follows: 19,209 graduates at the BD level of graduation $(65.4 \%$ of the total population of graduates), 8,175 graduates $(27.8 \%)$ at the MD level. $6.8 \%$ of graduates belongs to the Laurea Unica (LU) university course (a single 5 year cycle programme, with no possibility of interrupting studies after 3 years). These graduates were excluded from our analyses.

\subsection{Variables}

The dataset contains information on the University awarding the degree, the typology of the degree course, experiences during the study program (internship, studying in a foreign country, working, ...), graduate satisfaction concerning the course, other information concerning the status of the respondent,

\footnotetext{
${ }^{10}$ STELLA is the acronym of Statistica in TEma di Laureati $e$ Lavoro. It is a joint project coordinated by the CILEA Interuniversity Consortium (for further information see: http://www.cilea.it/1/). The consortium was established in 1974 and it groups eleven Italian universities. CILEA undertakes various studies, including a survey on final year student satisfaction, a survey on post-graduate employment, and a study of graduates' profiles based on administrative data. Since 2012 CILEA has been incorporated into CINECA. For detailed comments about survey results and for an overview of the data collection methodology, see STELLA $(2009,2010,2011)$, and previous years volumes.
} 
the type of current employment, company size, the work place, salary level, autonomy at work, job satisfaction, continuity between work and studies, and so on.

The main subject of our study is, for both groups of graduates considered in our analysis, the variable Work. It is a dichotomous variable that corresponds to the status of graduates 12 months after graduation. This variable is recoded into the following categories: $0=I$ 'm currently not working; $1=I$ am currently working and in our study it is used as a criterion variable to profile graduates. With this variable as a basis, we also computed the employability rate (e.r., in the following), that is, the rate of working graduates belonging to a certain group. This last variable is useful in ranking the main groups of graduates.

With regard to segmentation variables for profiling graduates, we initially consider a group of 19 variables, given in Table 1 .

Table 1 Segmentation variables for graduate profiling

\begin{tabular}{|c|c|c|c|}
\hline Variable & Type & Description & Categories \\
\hline Indep & dichotomous & graduate independence & $\begin{array}{c}\mathbf{1}=\text { living alone }+ \text { with a partner }+ \text { sharing a } \\
\text { flat } / \\
\mathbf{0}=\text { living with parents }\end{array}$ \\
\hline FathStud & 4 point scale & level of study of the respondent's father & \\
\hline MothStud & 4 point scale & mothers' level of study & \\
\hline FathEmpl & & father's type of employment & high level / low level / unemployed \\
\hline MothEmpl & & mother's type of employment & high level / low level / unemployed \\
\hline PartOrient & dichotomous & $\begin{array}{c}\text { participation in orientation cours- } \\
\text { es/activities }\end{array}$ & $\begin{array}{c}\mathbf{1}=\text { yes } / \\
\mathbf{0}=\text { no }\end{array}$ \\
\hline ForStud & dichotomous & $\begin{array}{c}\text { experience of study in a foreign country } \\
\text { while at university }\end{array}$ & $\begin{array}{c}\mathbf{1}=\text { yes } / \\
\mathbf{0}=\text { no }\end{array}$ \\
\hline WorkStud & & $\begin{array}{l}\text { employment of the interviewee during } \\
\text { studies (from enrollment to the date of } \\
\text { graduation) }\end{array}$ & $\begin{array}{c}\mathbf{1}=\text { yes } / \\
\mathbf{0}=\text { no; it also distinguishes between perma- } \\
\text { nent and temporary employment }\end{array}$ \\
\hline LookJob & dichotomous & respondent is seeking employment & $\begin{array}{c}\mathbf{1}=\text { yes } / \\
\mathbf{0}=\text { no }\end{array}$ \\
\hline Study & dichotomous & $\begin{array}{l}\text { graduate is studying at the time of the } \\
\text { interview }\end{array}$ & $\begin{array}{c}\mathbf{1}=\text { yes } / \\
\mathbf{0}=\text { no }\end{array}$ \\
\hline JobTipol & dichotomous & job typology at the time of the interview & $\begin{array}{c}\mathbf{0}=\text { part-time } / \\
\mathbf{1}=\text { full time } \\
\end{array}$ \\
\hline SalaryClass & three classes & current salary of respondent & $\begin{array}{l}0 \text { to } 1,000 € / 1.001 \text { to } 2,000 € / \text { more than } \\
2,000 €\end{array}$ \\
\hline JobSect & dichotomous & working sector & $\begin{array}{c}\mathbf{1}=\text { private } / \\
\mathbf{0}=\text { public }\end{array}$ \\
\hline GradNec & 3 point scale & need of the graduate to find employment & $\begin{array}{c}\mathbf{0}=\text { not necessary } / \\
\mathbf{1}=\text { preferable } / \\
\mathbf{2}=\text { necessary }\end{array}$ \\
\hline JobSatisf & dichotomous & job satisfaction & $\begin{array}{l}\mathbf{0}=\text { not completely satisfied }+ \text { not at all } \\
\text { satisfied } / \mathbf{1}=\text { quite satisfied }+ \text { very satisfied }\end{array}$ \\
\hline EnrollAgain & dichotomous & $\begin{array}{l}\text { graduates would want to enroll again in } \\
\text { the same course, whether he/she would } \\
\text { return to the course (level of satisfaction) }\end{array}$ & $\begin{array}{l}\mathbf{1}=\text { yes } / \\
\mathbf{0}=\text { no }\end{array}$ \\
\hline $\begin{array}{l}\text { ReasonMD } \\
\text { (BD only) }\end{array}$ & & $\begin{array}{l}\text { main reason motivating the graduate to } \\
\text { continue course studies (specialization } \\
\text { level) }\end{array}$ & $\begin{array}{c}\text { to complete education / necessary for access } \\
\text { to the job market / difficult to find employ- } \\
\text { ment / other reasons }\end{array}$ \\
\hline Internship & dichotomous & $\begin{array}{c}\text { respondent has had any work placement } \\
\text { experience }\end{array}$ & $\begin{array}{c}\mathbf{1}=\text { yes, while studying }+ \text { yes, after gradua- } \\
\text { tion } / \\
\mathbf{0}=\text { no }\end{array}$ \\
\hline DiscGroup & & $\begin{array}{l}\text { disciplinary group to which the graduate's } \\
\text { course belongs }\end{array}$ & $\begin{array}{c}\text { Agriculture / Architecture / Chemistry- } \\
\text { Pharmaceutics / Economics-Statistics / } \\
\text { Engineering / Geo-Biology / Languages / } \\
\text { Law / Literature / Medicine / Physical } \\
\text { Education / Psychology / Science / Socio- } \\
\text { Politics / Teaching }\end{array}$ \\
\hline
\end{tabular}




\section{Results of segmentation analysis}

Survey data allows first general groups of graduates to be identified based on employment status and study status (whether or not following more advanced studies, e.g., an MD specialised degree, or other specialized courses such as $\mathrm{PhD}$ or MSc courses). In some cases these categories may overlap (see Tables 2 and 3 for more details).

Nevertheless, this work focuses chiefly on the study of the Work variable (the criterion variable of the CHAID algorithm). Therefore we give priority to the employment status, using, for the first part of our study, a classification of units differing partly from that of STELLA. The latter is based on the classification of the population into two categories: the Labour Force $=L F$ and the Not-Labour Force $=N L F .^{11}$ For the purposes of our study, we also include those currently employed, although also studying or seeking alternative employment, in the group of employed. Nevertheless, from this population we exclude respondents who are seeking a job and are currently unemployed. Two main reasons are behind this decision: first, we presume that certain students (that is, graduates continuing with studies) may also be included in the labour market, given that they may maintain a previous job position or seek a job, and thereby potentially influence the labour market; additionally, we wish to evaluate the effectiveness of Universities and their impact on the employability of graduates, which is to say, we wish to evaluate those factors encouraging the employment of graduates, and therefore we include graduates who are without work in the unemployment group, even though they may be actively looking for a job (that is, even if they are considered part of the LF).

For these reasons, we decided to initially include the whole population of graduates (LF + students) in the segmentation procedure.

\footnotetext{
${ }^{11}$ According to the STELLA project, the $L F$ group includes the employed (people who have a job) and the unemployed (that is, people without work who are actively seeking a job and are available for work, aged between 15 and 70). Whereas the $N L F$ group includes people that are neither employed nor looking for a job, or people under 15 or over 70 (if not employed or seeking a job). For further information on the LF definition, see also the Eurostat website (http://epp.eurostat.ec.europa.eu/portal/page/portal/employm ent_unemployment 1fs/methodology/definitions) and The European Union lābour force survey - Methods and definitions - 2001, European Commission (2003), available online at: http://epp.eurostat.ec.europa.eu/cache/ITY_OFFPUB/ KS-BF-03-002/EN/KS-BF-03-02-EN.PDF).
}

If we take a look at the level of employment for the two groups of graduates, we notice that $36.8 \%$ of $\mathrm{BD}$ respondents were working at the time of the interview (12 months after graduation); the corresponding percentage for MD graduates is $64.9 \%$. Thus, the percentage of graduates not working is $63.2 \%$ for $\mathrm{BD}$ and $35.1 \%$ for MD (missing data: $5 \%$ for BD, $16.2 \%$ for MD).

The distribution by Work, LookJob and Study of both groups of graduates is shown in more detail in Table 2 (BD graduates) and Table 3 (MD graduates).

If we consider only the group of not workers (the first part of Table 2), the majority of BD graduates $(88.2 \%)$ have completed the first 3 years of university and are continuing studies with the following two years (MD). Whereas, the percentage of not-working graduates still studying after MD graduation is considerably smaller: $55.1 \%$ (first part of Table 3 ). This means that one of the main factors that can significantly influence the employability of the whole group of graduates is the possibility of continuing studies.

Table 2 Percentage distribution of BD graduates (by Work, LookJob, and Study)

\begin{tabular}{|l|c|c|c|c|}
\hline \multicolumn{2}{|c|}{} & \multicolumn{3}{|c|}{ Studying } \\
\hline \multirow{2}{*}{ Working } & LookJob & $\begin{array}{c}\text { Not } \\
\text { Studying }\end{array}$ & Studying & Total \\
\hline \multirow{3}{*}{$\begin{array}{l}\text { Not } \\
\text { working }\end{array}$} & Not looking & 0 & 80.7 & 80.7 \\
\cline { 2 - 5 } & Looking & 11.8 & 7.5 & 19.3 \\
\cline { 2 - 5 } & Total & 11.8 & 88.2 & 100.0 \\
\hline \multirow{3}{*}{ Working } & Not looking & 67.2 & 21.5 & 88.7 \\
\cline { 2 - 5 } & Looking & 8.9 & 2.4 & 11.3 \\
\cline { 2 - 5 } & Total & 76.0 & 24.0 & 100.0 \\
\hline
\end{tabular}

Table 3 Percentage distribution of MD graduates (by Work, LookJob, and Study)

\begin{tabular}{|c|c|c|c|c|}
\hline \multicolumn{2}{|c|}{} & \multicolumn{3}{|c|}{ Studying } \\
\hline \multirow{2}{*}{ Working } & LookJob & $\begin{array}{c}\text { Not } \\
\text { Studying }\end{array}$ & Studying & Total \\
\hline \multirow{3}{*}{$\begin{array}{c}\text { Not } \\
\text { working }\end{array}$} & Not looking & 0 & 49.9 & 49.9 \\
\cline { 2 - 5 } & Looking & 44.9 & 5.2 & 50.1 \\
\cline { 2 - 5 } & Total & 44.9 & 55.1 & 100.0 \\
\hline \multirow{3}{*}{ Working } & Not looking & 81.2 & 5.2 & 86.4 \\
\cline { 2 - 5 } & Looking & 12.6 & 1.0 & 13.6 \\
\cline { 2 - 5 } & Total & 93.8 & 6.2 & 100.0 \\
\hline
\end{tabular}

In fact, if we go deeper into the results, we notice that after the BD the likelihood of seeking employment (variable LookJob) or working (Work) is very low for graduates continuing with studies: only $8.8 \%$ of studying graduates were seeking a job (and 13.6\% were working). A quite different situation is shown for MD graduates who continue with studies: they have 
a similarly low likelihood of seeking employment $(10.6 \%)$, but a higher percentage is working (17.3\%).

No big differences are registered for the notstudying groups of $\mathrm{BD}$ and $\mathrm{MD}$ graduates. Among $\mathrm{BD}$ graduates not studying the percentage of people looking for a job was $30.3 \%$ and the percentage of workers was $78.9 \%$. Similar levels were registered for not-studying MD graduates: $31.2 \%$ were looking for a job and $79.4 \%$ were working.

These initial results suggest that one of the most discriminant variables with respect to the criterion variable (Work) is Study.

Having established these general findings concerning the population involved in the survey, in the following pages we give the main results obtained through the application of the CHAID algorithm. In particular, in $\S 4.1$ we discuss the main findings obtained studying the whole group of BD and MD graduates: within the list already introduced, the main discriminant variables with relation to the criterion variable (Work) are identified. Additionally, the characteristics of the main groups of units are given, focusing in particular on their level of employability. In $\S 4.2$, analysis is repeated excluding a variable (Study) for reasons explained below. A similar criterion lies behind a continuation of analysis excluding ReasonMD from the list of potential segmentation variables for the BD group (see the same $\S 4.2$ for results). In $\S 4.3$, analysis is carried out focusing, for both the $\mathrm{BD}$ and $\mathrm{MD}$ groups, on the LF only, that is, on graduates looking for a job or working at the time of the interview.

\subsection{BD \& MD graduates segmentation (all varia- bles)}

In this paragraph, the main general results referred to the whole group of BD and MD graduates are presented.

Although our objective is to study graduates that enter the labour market, in the first step of analysis we decided to include the whole population of graduates. We started with this wider approach mainly to test whether the two groups of graduates, those continuing with studies and those entering the labour market, would empirically emerge as two truly different groups. The first run of the CHAID algorithm confirms this hypothesis.

The analysis considers the entire $\mathrm{BD}$ and $\mathrm{MD}$ groups of respondents and all 19 independent variables quoted in $\S 3.1$. After 3 steps of the segmentation procedure, 24 nodes (and 17 terminal nodes) are identified for BD graduates, whereas 18 nodes and 11 terminal nodes are identified for the MD group. Considering Work as the criterion variable, the varia- bles included (and their order of importance) are the following independent variables.

- For BD graduates: Study, LookJob, WorkStud, ReasonMD, DiscGroup.

- For MD graduates: Study, LookJob, WorkStud, ForStud, MothEmpl.

Therefore the first variable selected to create a split within the whole group of BD and MD respondents is Study. This is an obvious choice: a graduate who is not studying is more likely to work than a student who is studying (who has less time available if he/she wishes to complete the course as soon as possible); moreover, the percentage of students is lower if respondents are working $(24.0 \%$ for $\mathrm{BD}$ and $6.2 \%$ for $\mathrm{MD})$ than if they are not working $(88.2 \%$ for BD and $55.1 \%$ for $\mathrm{MD})$. These conclusions are confirmed by the strong negative correlation between the variables Study and Work (Pearson correlations: BD group $=-0.660 ; p<$ $0.000 ;$ MD group $=-0.551 ; p<0.000$ ).

Analysis empirically proves that the first segmentation variable is $S t u d y$. Following this, the study goes on to focus on a double objective: to study in greater depth the characteristics both of graduates who have actually entered the labour market and those who continue with studies.

If we exclude the obvious selection of Study as first discriminant variable, it is also interesting to observe the detailed hierarchy of the selected segmentation variables, summed-up in Figure 1 (BD graduates) and Figure 2 (MD graduates): in the two schemes, it is possible to identify the most discriminant variable with respect to the criterion variable for each group and subgroup of units. In each node of the tree, the first part describes the group/subgroup, whereas the second part shows the variable selected for segmenting that specific group/subgroup. The differences between BD and MD graduates are highlighted, in the nodes of Figure 2, by a darker background.

For the first two levels of the CHAID algorithm, the selected variables for both $\mathrm{BD}$ and MD graduates are the same. The most discriminant variable in connection with Work, that is, Study, divides the original group into two sub-groups: studying and notstudying graduates. For graduates still studying the most important variable linked to Work is WorkStud: probably students that had a temporary or continuative job while studying are more likely to keep their job after graduation, if they decide to continue studying. On the other hand, for graduates that have finished or stopped studies, the most discriminant variable is looking for a job (LookJob divides graduates not studying into two homogeneous groups related to Work). 


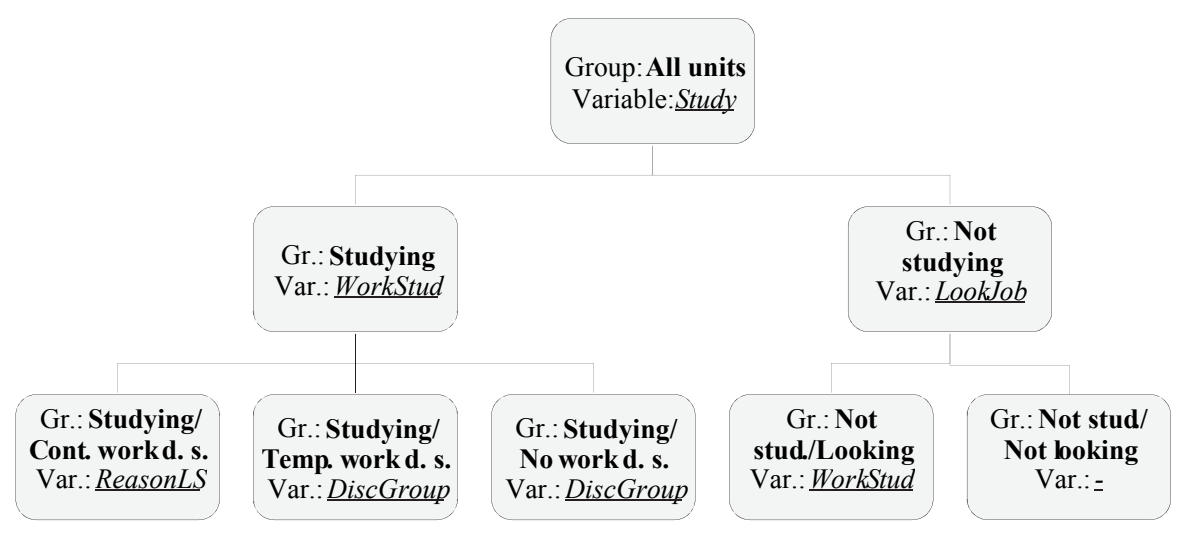

Figure 1 Hierarchy of the segmentation variables - BD Graduates (CHAID; dependent var.: Work; independent var.: all other variables)

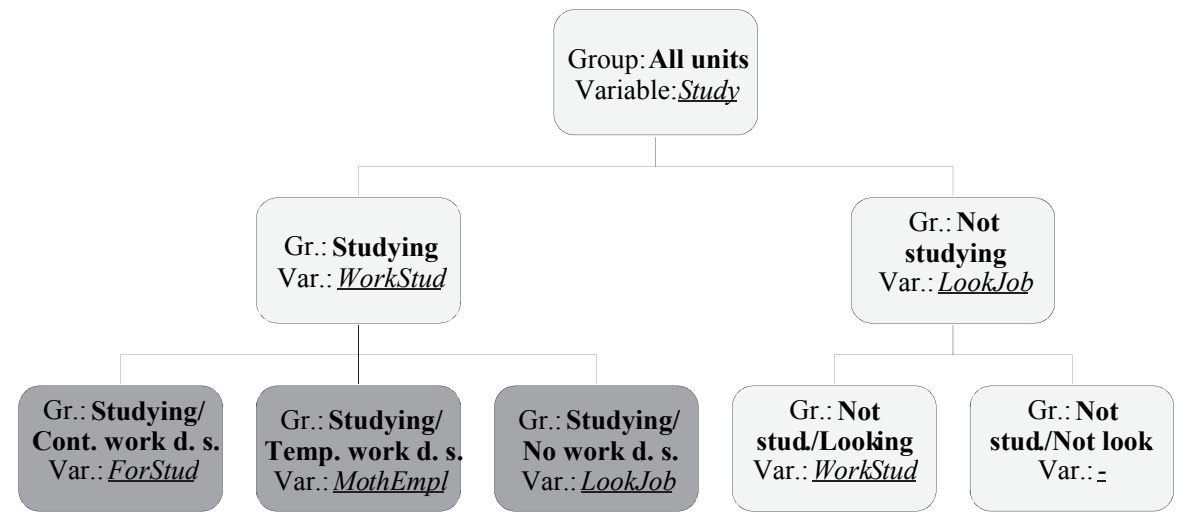

Figure 2 Hierarchy of the segmentation variables - MD Graduates (CHAID; dependent var.: Work; independent var.: all other variables)

At the third level, both for BD and MD graduates, WorkStud emerges once more as the most discriminant variable for graduates who are not studying and are seeking employment. Probably previous experience in the labour market increases the likelihood of having a job one year after the graduation also in the case of graduates without a job who are looking for one.

The first difference between BD and MD graduates emerges, at the third level, for graduates who continue studying.

For BD graduates who have had continuative paid employment while attending university, the segmentation variable is ReasonMD, whereas for the corresponding group of MD graduates it is ForStud. This once more underlines that for BD graduates employment is correlated to reasons linked to a decision to pursue studies; whereas for MD graduates the percentage of employed graduates is influenced by previous study experience abroad.

For BD graduates who have had a temporary job or have not had a job while attending university, the most discriminant variable is DiscGroup (even if differently recoded: this implies a need for further research into segmentation by disciplinary group). On the other hand, for MD graduates who have had a temporary job while at university the selected segmentation variable is MothEmpl (indicating that the mother's employment level seems to have an influence on graduate employability), and for those who have not had a job during courses, LookJob is selected (in fact, these graduates are more likely to be involved, following graduation, in the activity of seeking a new job).

In the first part of this section we highlighted the most discriminant variables (and their hierarchy) in relation to the criterion variable (Work), the main objective of our study. But following these general findings, we wish to focus more on the groups obtained by segmentation. Which are the groups of BD and MD graduates more likely to be employed one year after graduation? And what are their main characteristics? This could be determined by observing the segmentation results summarized in Table 4 (referring to the $\mathrm{BD}$ group) and in Table 5 (the MD group). In the two tables we list all terminal nodes obtained via analysis (the number of the node is in the second 
Table 4 Rank of groups by e.r. and description (BD graduates)

\begin{tabular}{|c|c|c|c|c|c|c|}
\hline & & & & \multicolumn{3}{|c|}{ Group profile } \\
\hline \# & Node & $\%$ & e.r. & Level 1 & Level 2 & Level 3 \\
\hline 0 & Root & 100.0 & 0.366 & - & - & - \\
\hline 1 & 3 & 24.5 & 1.000 & Not studying & Not looking & - \\
\hline 2 & 13 & 0.2 & 0.857 & Studying & Cont. w.d.u. & Difficulty in getting a job \\
\hline 3 & 18 & 0.2 & 0.698 & Studying & Temp. w.d.u. & Medicine \\
\hline 4 & 8 & 1.7 & 0.542 & Not studying & Looking & Cont. w.d.u. \\
\hline 5 & 11 & 5.3 & 0.540 & Studying & Cont. w.d.u. & $\begin{array}{c}\text { Complete/enrich instruc- } \\
\text { tion }\end{array}$ \\
\hline 6 & 23 & 1.1 & 0.467 & Studying & No w.d.u. & Medicine \\
\hline 7 & 16 & 0.3 & 0.404 & Studying & Temp. w.d.u. & Physical Education \\
\hline 8 & 12 & 2.3 & 0.391 & Studying & Cont. w.d.u. & Need to get a job \\
\hline 9 & 9 & 2.4 & 0.382 & Not studying & Looking & Temp. w.d.u. \\
\hline 10 & 22 & 1.2 & 0.269 & Studying & No w.d.u. & Teaching \\
\hline 11 & 17 & 1.5 & 0.263 & Studying & Temp. w.d.u. & Teaching, Psychology \\
\hline 12 & 10 & 6.5 & 0.209 & Not studying & Looking & No w.d.u. \\
\hline 13 & 14 & 5.7 & 0.166 & Studying & Temp. w.d.u. & $\begin{array}{c}\text { Agriculture, Architecture, } \\
\text { Chemistry-Pharmaceutics, } \\
\text { Geo-Biology, Literature, } \\
\text { Socio-Politics }\end{array}$ \\
\hline 14 & 15 & 5.2 & 0.125 & Studying & Temp. w.d.u. & $\begin{array}{c}\text { Economics-Statistics, Law, } \\
\text { Engineering, Languages, } \\
\text { Science }\end{array}$ \\
\hline 15 & 21 & 3.0 & 0.094 & Studying & No w.d.u. & $\begin{array}{c}\text { Psychology, Physical } \\
\text { Education }\end{array}$ \\
\hline 16 & 19 & 25.9 & 0.051 & Studying & No w.d.u. & $\begin{array}{c}\text { Agriculture, Architecture, } \\
\text { Economics-Statistics, Law, } \\
\text { Literature, Languages, } \\
\text { Socio-Politics, Science } \\
\end{array}$ \\
\hline 17 & 20 & 13.1 & 0.022 & Studying & No w.d.u. & $\begin{array}{l}\text { Chemistry-Pharmaceutics, } \\
\text { Geo-Biology, Engineering }\end{array}$ \\
\hline
\end{tabular}

Table 5 Rank of groups by e.r. and description (MD graduates)

\begin{tabular}{|c|c|c|c|c|c|c|}
\hline \multirow[b]{2}{*}{ \# } & \multirow[b]{2}{*}{ Node } & \multirow[b]{2}{*}{$\%$} & \multirow[b]{2}{*}{ e.r. } & \multicolumn{3}{|c|}{ Group profile } \\
\hline & & & & Level 1 & Level 2 & Level 3 \\
\hline 0 & Root & 100.0 & 0.650 & - & - & - \\
\hline 1 & 3 & 53.0 & 1.000 & Not studying & Not looking & - \\
\hline 2 & 8 & 3.1 & 0.594 & Not studying & Looking & Cont. w.d.u. \\
\hline 3 & 11 & 2.3 & 0.504 & Studying & Cont. w.d.u. & No study foreign c. \\
\hline 4 & 9 & 6.5 & 0.443 & Not studying & Looking & Temp. w.d.u. \\
\hline 5 & 14 & 2.2 & 0.319 & Studying & Temp. w.d.u. & $\begin{array}{l}\text { Medium/low level mother } \\
\text { employment }\end{array}$ \\
\hline 6 & 12 & 0.6 & 0.243 & Studying & Cont. w.d.u. & Study foreign c. \\
\hline 7 & 10 & 14.1 & 0.234 & Not studying & Looking & No w.d.u. \\
\hline 8 & 17 & 1.4 & 0.188 & Studying & No w.d.u. & Looking \\
\hline 9 & 13 & 0.9 & 0.158 & Studying & Temp. w.d.u. & Mother not working \\
\hline 10 & 15 & 1.9 & 0.148 & Studying & Temp. w.d.u. & $\begin{array}{l}\text { High level mother } \\
\text { employment }\end{array}$ \\
\hline 11 & 16 & 14.0 & 0.096 & Studying & No w.d.u. & No looking \\
\hline
\end{tabular}


column) and their rank (first column) referred to the employability rate (e.r. ${ }^{12}$, fourth column); in the third column one can find the percentage of graduates of the $\mathrm{BD} / \mathrm{MD}$ population belonging to the considered node. The last three columns of the tables show the main characteristics of the nodes by means of segmentation variable category.

For BD graduates, node 3 (or \#1) represents full employability, which refers to graduates no longer studying and not looking for a new job because they have an occupation. Since at this step of our study we consider all graduates, even those who are undertaking further studies and not actively seeking employment, CHAID analysis shows that nodes with higher employability are those related to graduates who worked while studying (especially in permanent employment) although continuing education. For graduates entering the labour market (i.e., not studying) and looking for a job, employability is far below a high level. The highest level is assigned to those working continuously while studying (e.r. 0.542 , that is, in that specific group $54.2 \%$ of those interviewed are working), whereas those who were not working at all are at a level of 0.209 and in an intermediate position (e.r. 0.382 ) if they had temporary employment. These findings once more underline the importance of previous work experience during studies in easing the employability of graduates 12 months after the graduation.

Also in the case of MD graduates, node 3 (\# 1 in the rank) represents full employability and includes graduates who are not studying and are not looking for a new position. If we focus, in particular, on notstudying and looking-for-a-job graduates, we notice, again, that work experience during studies is actually highly correlated with the employability level. Those graduates who have had continuative work positions during studies register the highest employment level $(59.4 \%)$; graduates whose have worked temporarily during university courses show a much lower employment rate (0.443); finally the percentage of employed graduates within the group that has had no work experience during the university courses is the lowest (23.4\%). If we consider graduates undertaking further advanced studies ( $\mathrm{PhD}, \mathrm{MSc}$, and so on), the percentage of employed in the group that has had continuative work experience during studies is higher as well: $50.4 \%$ of graduates who have had no study experience abroad, $24.3 \%$ for those who have. These latter statistics might seem surprising, but in fact are not: for those who have a continuative job, it is diffi-

12 The employment rate (e.r.) has been already introduced in $\S 3.1$ : it is the rate of working graduates (12 months after graduation) belonging to a specific group of graduates. cult (if not impossible) to go abroad for new study experiences, if they want to keep their positions. This explains why graduates with no study experience abroad show higher e.r.s. For people who have had temporary jobs during studies, employability is, on average, lower (e.r. between 0.148 and 0.319). The lowest level of employability is registered for studying graduates with no previous work experience during studies (e.r. between 0.096 and 0.188).

\subsection{BD \& MD graduates: Study excluded}

The main findings of the previous section was that the two most discriminant variables, in relation to Work, are WorkStud and, especially, Study. This, of course, means that the two subgroups of studying and notstudying graduates differ a lot in relation to the Work variable, and this result is perfectly comprehensible. But what happens if we exclude the most significant variable (Study) from segmentation analysis? In Figure 3 (for BD graduates) and Figure 4 (for the MD group) the hierarchy of segmentation variables is shown. Again, the differences between BD and MD graduates are highlighted, in Figure 4, by a darker background.

Observing this last tree, we immediately notice that the segmentation of $\mathrm{BD}$ and MD groups is completely different. In fact, if the variable Study is excluded from analysis, the first segmentation variable is ReasonMD for $\mathrm{BD}$ graduates (Figure 3) and Look$J o b$ for the MD group (Figure 4). Closer examination shows that the root of the BD group is segmented into three categories with respect to a reclassified version of the reasons behind the decision to continue with studies: 1) to complete education, 2) it is mandatory choice to find a job, 3) it is difficult to find a job + for other reasons. Again, if we exclude Study from analysis, the variable most linked to it emerges as the main segmentation variable (strongly linked to the criterion variable). For MD graduates on the other hand, the main option after 5 years of study is, of course, looking for a job (LookJob), and this activity is most certainly linked strongly with the employment choice of the interviewee: this can explain why this variable is selected as the first segmentation variable (Figure 4).

At the second level of BD segmentation, for the first and second classes of ReasonMD, the variable WorkStud is selected. This confirms that the presence of a continuous rather than a temporary job, more than the absence of work experience during studies, has notable effects on graduate employability. For the remaining group (people who continue studies because of difficulties in finding a job and for other reasons) the main segmentation variable is LookJob. 


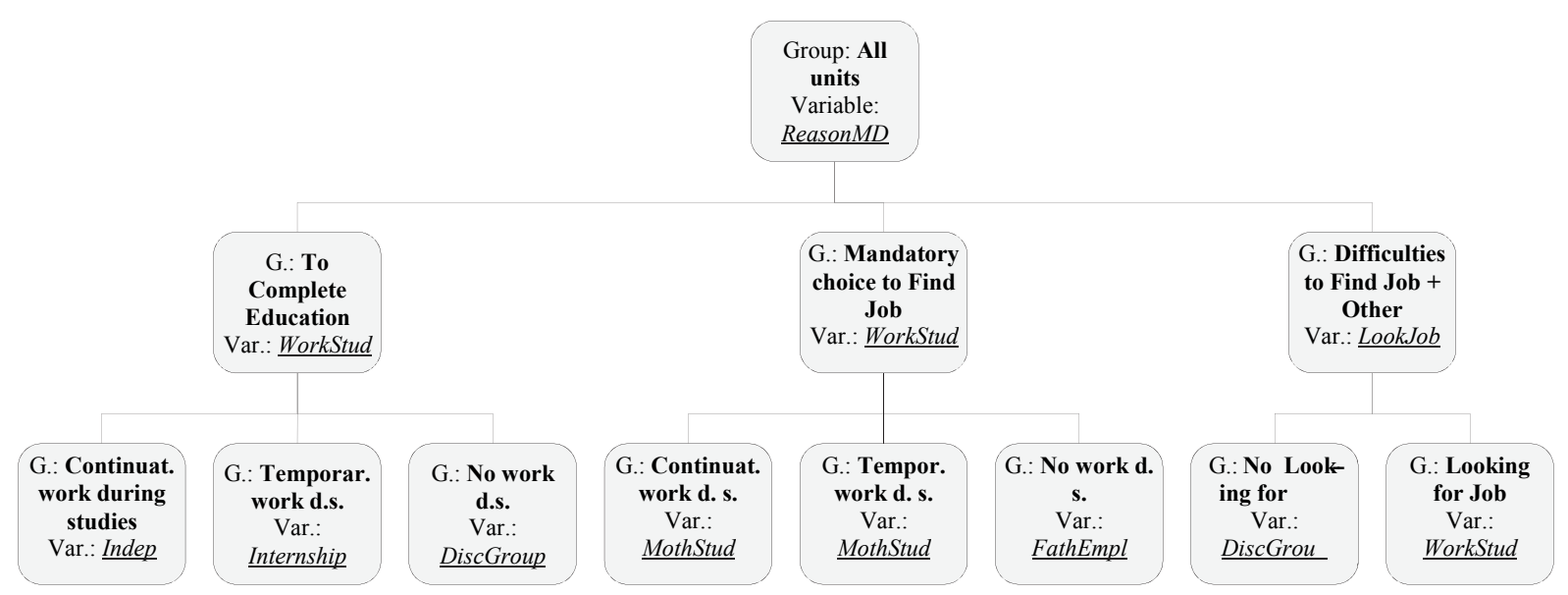

Figure 3 Hierarchy of the segmentation variables for BD graduates (CHAID; dependent var.: Work; independent: all variables, Study excl.)

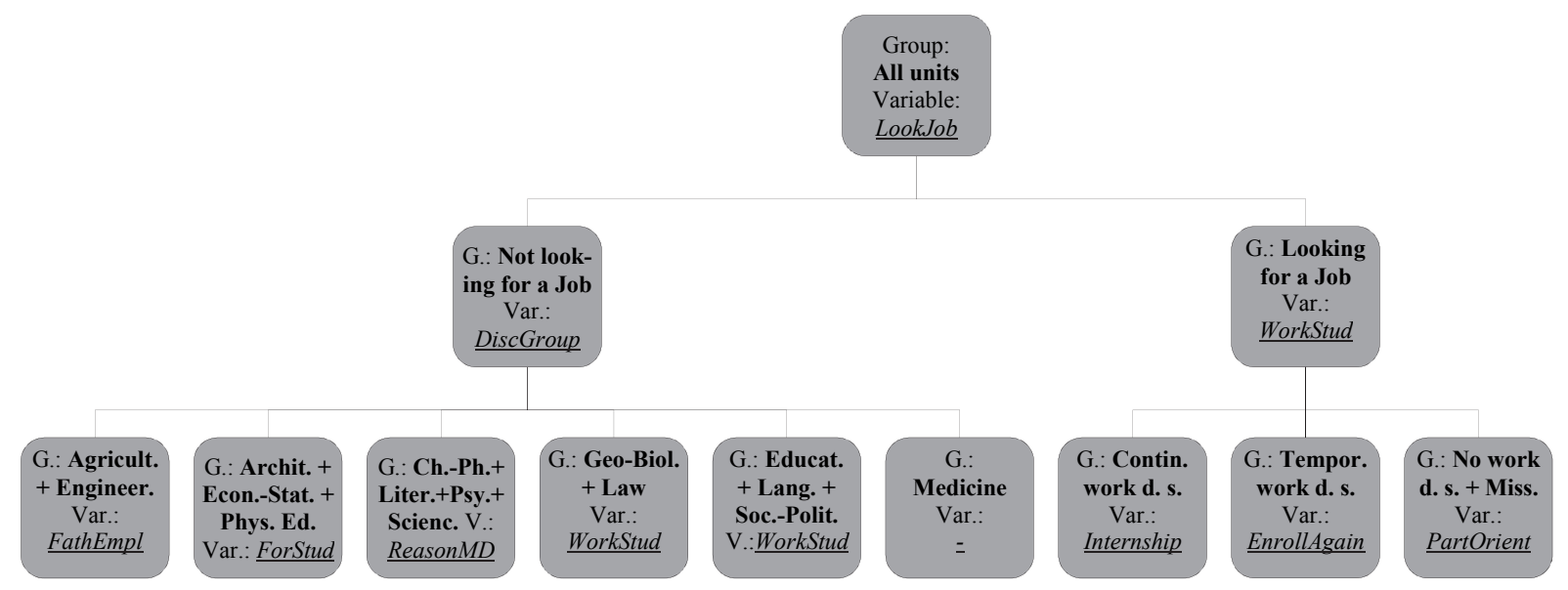

Figure 4 Hierarchy of the segmentation variables for MD graduates (CHAID; dependent var.: Work; independent: all variables, Study excl.)

The importance of the variable WorkStud is also underlined by the tree of the MD graduates (Figure 4): it is the variable most related to the employability of graduates seeking a job (right branch of the tree): this can be explained analogously to what has been stated above and it once more reinforces the conclusion that graduate work experience while at university is strictly linked to employability. The second level of the segmentation analysis selects, for graduates not looking for a job (see the left branch of the tree in Figure 4), a reclassified version of the disciplinary group variable (DiscGroup).

At the third, and last step, of analysis, the two most important variables to emerge for BD graduates are (with occurrences in brackets): the disciplinary groups (DiscGroup, 2), and the level of Mother's education (MothStud, 2). Other important variables are the level of Father's employment (FathEmpl, 1), work experience during studies (WorkStud, 1), the presence of an internship experience (Internship, 1), student inde- pendence, meaning whether or not a student is living with parents (Indep , 1); the latter emerges, for the first time, for students with continuative work experience during the university.

For MD graduates, the highest occurrences at the third level of segmentation are observed for the variable WorkStud (2), while the other selected variables are: FathEmpl (1), ForStud (1), and ReasonMD (1) (for the DiscGroup branch) and Internship (1), EnrollAgain (1), and PartOrient (1) (for the WorkStud side).

Summarizing the segmentation results, the three highest and the three lowest e.r.s observed are shown in Table 6 (for BD graduates, with 23 terminal nodes) and Table 7 (for MD graduates, with 22 terminal nodes). In the tables, the percentage of graduates belonging to each node and node descriptions are also shown.

The three highest, e.r.s all comprise students that found difficulties in finding a job or decided to con- 
tinue studying for other reasons; moreover they are not seeking a job and mostly belong to the teaching, medicine or science disciplinary groups (Table 6). The three lowest, e.r.s include students who consider an advanced MD course as a way of completing their education, or there is a mandatory decision to find a job; they have all also had no work experience during BD courses.

The top groups of graduates (by e.r.) are not looking for a job, and though they have sometimes had continuative jobs while studying, they have not usually had study experiences abroad. The lowest e.r.s correspond to graduates who are usually looking for a job (nodes 31 and 29), who did not participate in orientation activities, who mostly consider advanced studies useful in completing education, and who are usually dissatisfied with the course (they would not enroll in the course again, were they able to go back and start over).

\subsection{BD \& MD graduates: labour force analysis}

One might think that the differences in segmentation of the two groups of graduates indicated in the previous paragraphs are due to the different structural compositions of the two populations: BD graduates are more likely to continue with studies, rather than enter the labour market, whereas the majority of MD graduates finish studies so as to enter the labour market (see Tables 2 and 3 for details). But what happens if we compare $\mathrm{BD}$ with MD graduates considering only those who actually entered the labour market (that is, those who are seeking a job, or working, at the time of the interview)? Thus, what happens if we limit the analysis only to the labour force?

The labour force is composed of the following groups:

- $8,940 \mathrm{BD}$ graduates $(75.1 \%$ of them are working, 33.4\% are looking for a job);

- 5,653 MD graduates (78.7\% of them are working, $32.0 \%$ are looking for a job).

At the first and at the second level of the CHAID algorithm, the same segmentation variables are selected for both $\mathrm{BD}$ and MD graduates.

The first segmentation variable chosen by the iterative process is LookJob. Thus, at the first step of analysis, we obtain two subgroups: the first one corresponding to graduates who are looking for a job $\left(33.5 \%\right.$ for $\mathrm{BD}$ and $31.7 \%$ for $\left.\mathrm{MD}^{13}\right)$, the second subgroup comprising graduates that are not looking

13 Differences in comparison with the previously listed percentages are caused by missing data related to the Work variable.

Table 6 Highest and lowest graduates groups by e.r. (BD graduates)

\begin{tabular}{|l|c|c|c|c|}
\hline$\#$ & Node & $\%$ & $e . r$. & Group description \\
\hline 1 & 30 & 9.6 & 0.977 & Difficult to find a job + other / Not looking / Teaching \\
\hline 2 & 29 & 2.2 & 0.950 & Difficult to find a job + other / Not looking / Medicine \\
\hline 3 & 31 & 1.5 & 0.908 & Difficult to find a job + other / Not looking / Science \\
\hline$\ldots$ & 16 & 14.8 & 0.053 & $\begin{array}{c}\text { To complete education / No w.d.u. / Agriculture+ Architecture+ Chem- } \\
\text { istry-Pharmaceutics+ Economics-Statistics+ Law+ Literature+ Science+ } \\
\text { Socio-Politics }\end{array}$ \\
\hline 22 & 25 & 13.4 & 0.036 & Mandatory choice to find job / No w.d.u. / No internship \\
\hline 23 & 18 & 8.7 & 0.021 & $\begin{array}{c}\text { To complete education / No w.d.u. /Engineering+ Geo-Biology+ } \\
\text { Languages }\end{array}$ \\
\hline
\end{tabular}

Table 7 Highest and lowest graduates groups by e.r. (MD graduates)

\begin{tabular}{|c|c|c|c|c|}
\hline \# & Node & $\%$ & e.r. & Group description \\
\hline 1 & 8 & 1.6 & 0.990 & Not looking / Medicine / \\
\hline 2 & 24 & 3.8 & 0.957 & $\begin{array}{c}\text { Not looking / Teaching+ Languages }+ \text { Socio-Politics / } \\
\text { Cont. w.d.u. }\end{array}$ \\
\hline 3 & 16 & 10.9 & 0.935 & $\begin{array}{c}\text { Not looking / Architecture+ Economics-Statistics }+ \\
\text { Physical Education / No foreign studies }\end{array}$ \\
\hline \multicolumn{5}{|l|}{$\ldots$} \\
\hline 20 & 31 & 9.7 & 0.193 & Looking / Temp. w.d.u. / No orientation activities \\
\hline 21 & 29 & 0.6 & 0.184 & Looking / No w.d.u. / No enrol again \\
\hline 22 & 18 & 0.7 & 0.048 & $\begin{array}{c}\text { Not looking / Chemistry-Pharmaceutics }+ \text { Literature+ Psychology+ } \\
\text { Science / To complete education }\end{array}$ \\
\hline
\end{tabular}


for a job (66.5\% for BD and $68.3 \%$ for MD). For both $\mathrm{BD}$ and $\mathrm{MD}$, there is no further segmentation of this last subgroup by the algorithm, because it is fully employed (e.r. $=1.0$ ).

On the other hand, the node corresponding to graduates who are looking for a job is further segmented, by means of the variable WorkStud, into three subgroups. The highest e.r. is observed for graduates having had a continuative job during studies (BD e.r.: 0.496; MD e.r.: 0.578). If the job was temporary, the percentage of employed is lower (BD: 0.317; MD: $0.427)$, and if there is no work experience, the e.r. is even smaller ( 0.161 for BD and 0.230 for MD).

The chief differences between working forces belonging to the $\mathrm{BD}$ and $\mathrm{MD}$ groups emerge at the third step of the CHAID algorithm. For BD and MD graduates who have had a continuative job the segmentation variables are, respectively, ReasonMD (for $\mathrm{BD}$ ) and Internship (for MD). For graduates who have had temporary jobs while at university, the variables Study (for BD) and EnrollAgain (for MD) are selected. And finally, for those who have had no job experiences during studies, the variables selected are: DiscGroup (for BD) and PartOrient (for MD).

Thus, if during the first two steps of analysis seeking a job and employment during studies are the variables most linked to graduate employability, at the third level the two groups of graduates differ. For BD the variables influencing the employment of graduates are mostly connected with the decision to pursue studies (ReasonMD and Study ${ }^{14}$ ) or with the fact of

14 The highest e.r.s are observed for graduates who have found difficulties in entering the job market or who contin- belonging to a certain disciplinary group $\left(\right.$ DiscGroup $^{15}$ ). On the other hand, for MD graduates, the level of employment is influenced mostly by university experiences that might encourage it, such as participation in orientation courses/activities (PartOrient) or other internship experiences (Internship); nevertheless, employment can also determine graduate satisfaction for the course (EnrollAgain).

Given that we are studying what universities can do to encourage the employment of its graduates, we can focus only on BD graduates who are still seeking a job (33.5\% of the total labour force), describing their main characteristics through the main terminal nodes obtained by analysis (they are shown in the second part of Table 8).

Again, the employability of graduates who are still seeking a job, in general, is in no way favored by the absence of work activity during studies. Moreover, the employment level varies considerably depending on the disciplinary group (ranging from $2.5 \%$ to $33 \%$ ): in particular, if graduates come from the disciplinary groups listed in nodes \#10 and \#11, the percentage of working graduates is equal to, respectively, $11.7 \%$ and $2.5 \%$. The highest e.r. $(0.550)$ corresponds to graduates who have had continuative employment while at university (w.d.u., in the table) and who decided to continue with studies (mainly as a result of difficulties experienced in seeking a job). For those who aim at completing education or who consider graduation

ued studies for other reasons (e.r. 0.550), and for those who are not studying (0.382).

${ }^{15}$ Chemical-Pharmaceutical, Medicine, and Science disciplinary groups show the highest average e.r. (0.330).

Table 8 Rank of groups by e.r. and description - BD graduates (labour forces only)

\begin{tabular}{|c|c|c|c|c|}
\hline \multirow[b]{2}{*}{ Node } & \multirow[b]{2}{*}{$\%$} & \multicolumn{3}{|c|}{ Group profile (description) } \\
\hline & & Level 2 & Level 3 & e.r. \\
\hline Labour force & 100.0 & & & 0.749 \\
\hline- Not look. job & 66.5 & & & 1.000 \\
\hline - Looking for job & 33.5 & & & 0.251 \\
\hline 7 & 3.8 & Cont. w.d.u. & Difficult to find a job + Other reasons + Missing & 0.550 \\
\hline 8 & 5.0 & Temp. w.d.u. & Not studying & 0.382 \\
\hline 6 & 1.6 & Cont. w.d.u. & $\begin{array}{l}\text { To complete the education + Necessary to have } \\
\text { access to the job market }\end{array}$ & 0.364 \\
\hline 12 & 3.6 & No w.d.u. & Chemistry-Pharmaceutics + Medicine + Science & 0.330 \\
\hline 9 & 2.8 & Temp. w.d.u. & Studying & 0.200 \\
\hline 13 & 4.6 & No w.d.u. & $\begin{array}{c}\text { Economics-Statistics + Geo-Biology + Law + } \\
\text { Physical Education }\end{array}$ & 0.192 \\
\hline 10 & 9.7 & No w.d.u. & $\begin{array}{c}\text { Agriculture + Engineering + Languages }+ \\
\text { Psychology }+ \text { Socio-Politics }+ \text { Teaching } \\
\end{array}$ & 0.117 \\
\hline 11 & 2.4 & No w.d.u. & Architecture + Literature & 0.025 \\
\hline
\end{tabular}


necessary in order to have access to the job market, the e.r. is also quite high (0.364).

Finally, for graduates who have had a temporary job while at university, two groups are defined with different employment levels. Graduates who are pursuing studies are less likely to be employed (20\%) than graduates who finished studies $(38.2 \%)$.

Table 9 shows the results obtained when considering MD graduates. The terminal nodes in the last rows of the table are the results of the segmentation of graduates seeking a job $(31.7 \%$ of the total labour force).

From this table we may observe, once again, that the presence of continuative employment during studies favors the e.r. $(>0.41)$, although an internship during, or following, studies seems to have the opposite effect ( 0.41 with internship, 0.645 without internship experiences). For those who had no job while at university, orientation activities and courses are useful in encouraging the e.r. (0.193 without orientation, 0.291 with orientation). For graduates who had temporary employment experiences during studies, there is a clear connection between employment level and the general satisfaction of graduates. The latter is probably influenced by the first: if the e.r. is high (0.450), the graduate would enroll again, but if it is smaller (0.184), he/she would not do so.

\section{Concluding remarks}

Our paper investigates the employability of BD and MD graduates, using variables collected by means of a survey of these populations one year after graduation. We apply CHAID, a well-known and efficient segmentation algorithm that can also be helpful in reclassifying the original variables' classes. We firstly aim at understanding which factors are most closely linked to graduate employability; moreover, our objective is to profile graduates with respect to the level of employment and to identify drivers for their employability. In the first part of this work, the whole population of graduates of both groups (BD and MD) is considered, whereas in the last part of the analysis we focus, mainly, on graduates belonging to the labour market (that is, who are working, or looking for a job, 12 months after graduation).

The CHAID algorithm shows, at its first step, the relevance of the variable Study in profiling both the BD and MD groups into two separate categories: notstudying and studying graduates. The second step of analysis shows, for both graduate groups, the importance of the variable looking for a job (for notstudying graduates) and of work experience while at university (for graduates who decided to continue with studies). The differences between $\mathrm{BD}$ and MD groups emerge at the third level of segmentation. The BD group is segmented by means of the variables reasons for further studies and disciplinary group, whereas the MD group is segmented by means of the variables studies in foreign countries, mother's employment level, and looking for a job.

But, in general, having had a job while studying is the most important factor: it can highly improve employability performance, above all if the job was not temporary.

When not explicitly considering whether graduates are continuing with studies (that is, if we exclude the variable Study from the algorithm), the two populations of BD and MD are segmented using a different set of variables. The BD group is identified by means of the variable reasons for further studies at the first level, by means of WorkStud and LookJob at the second level, and by means of a set of other variables at the third level (disciplinary group, level of mother's education, level of father's employment, work experiences during studies, independence of graduates, internship experience). On the other hand, the MD

Table 9 Rank of groups by e.r. and description - MD graduates (labour forces only)

\begin{tabular}{|l|c|c|c|c|}
\hline \multicolumn{2}{|c|}{} & \multicolumn{3}{|c|}{ Group profile (description) } \\
\hline Node & $\%$ & Level 2 & Level 3 & $0 . r$. \\
\hline Labour force & 100.0 & & & 0.788 \\
\hline- Not look. job & 68.3 & & & 0.331 \\
\hline- Looking for job & 31.7 & & No internship during/ after studies & 0.645 \\
\hline 7 & 3.0 & Cont. w.d.u. & Enroll again & 0.450 \\
\hline 9 & 7.9 & Temp. w.d.u. & Internship during/after studies & 0.413 \\
\hline 6 & 1.2 & Cont. w.d.u. & Orientation courses/activities & 0.291 \\
\hline 11 & 7.0 & No w.d.u. & No orientation courses/activities & 0.193 \\
\hline 10 & 11.8 & No w.d.u. & No enroll again & 0.184 \\
\hline 8 & 0.7 & Temp. w.d.u. & & \\
\hline
\end{tabular}


group is segmented, at the first level, using the dichotomous variable looking for a job, and, at the second level, by working while at university and by disciplinary group; at the third level, the algorithm underlines the importance of other variables: father's employment level, studying in foreign countries, internship experiences, graduate satisfaction, participation in orientation activities/courses.

Statistical analyses limited just to the group of those who were working or seeking a job at the time of the interview (that is, in the labour force) select, as best segmentation variables, looking for a job (first level) and working during studies (second level). In general, findings suggest that the factor which highly affects employability is, again, having had a job while studying (especially if the job was continuative). More specifically, this is to say that graduates who have had a continuative job during university show the highest e.r.; the level of employability is usually greater improved if graduates want to study to complete education (BD) and if there were no internship experiences during or after studies (MD). For graduates that have had a temporary job during university courses, the employment rate has a negative correlation with the decision of pursuing studies (BD), but it is positively correlated with graduate satisfaction (MD). For those who did not have a job during the courses, the e.r. shows different levels according to the disciplinary groups (BD) and is increased if graduates participated in orientation activities (MD).

In conclusion, our study confirms and quantifies the existing relationships between the labour market, participating in collateral university activities (orientation courses/activities, internships, studying abroad), student background (the independence of graduates, the father's level of employment, and the mother's level of education), and the decision (and related reasons) to pursue studies further. In addition, our study underlines the primarily relevant role of working during the studies.

Thus, generally speaking, it appears that there is a need to evaluate and encourage employability within a larger integrated framework: employability is about developing a range of attributes and abilities, not just job-getting skills. It involves developing a portfolio of experiences, not being something distinct from learning and pedagogy, but rather growing out of good learning. This all underlines the significance of an integrated approaches to employability, possibly studying the employability process and using a conceptual model that offers a framework for identifying the main factors that may influence labour market transitions for individuals (Forrier and Sels, 2003; Dacre Pool and Sewell, 2007b).
The results achieved represent a useful decisional support in terms of understanding that the interaction between the labour market, the university environment and family characteristics is of fundamental importance as regards graduate employability. Moreover, the need to stimulate students into having an initial work experience during studies emerges (even if the work is temporary, the e.r. is increased), and universities should invest more in (and plan and develop more) orientation activities and courses. Post-graduate employability is also correlated significantly with student satisfaction.

Starting from the results obtained in this study, research could be furthered by applying logistic regression analysis to the data, considering graduate employment as a dependent variable and using a broader group of variables as independent ones. During analysis, disciplinary groups emerged several times as an important segmentation variable: further study should investigate (by means of both the CHAID segmentation algorithm and logistic regression analysis) the specific factors behind employability in each disciplinary group.

\section{References}

BETTS, J., FERRALL, C., FINNIE, R. (2000). The transition to work for Canadian university graduates: Time to first job, 1982-1990. Analytical Studies Branch Research Paper Series, No. 2000141e. Ottawa: Statistics Canada, analytical studies branch.

BIGGERI, L., BINI, M., GRILLI, L. (2001). The transition from University to work: A multilevel approach to the analysis of the time to obtain the first job. Journal of the Royal Statistical Society 164(2): 293-305. http://dx.doi.org/10.1111/1467-985X.00203

BIGGERI, L., BINI, M. (2003). Performance evaluation of the university system in Italy: A robust clustering approach to validate homogeneous groups of units. Proceedings of the Joint Statistical Meetings of the American Statistical Association, 3-7 August 2003. San Francisco: MIRA: Digital Publishing, 1-7.

BINI, M., CHIANDOTTO, B. (2003). La valutazione del sistema universitario Italiano alla Luce della riforma dei cicli e degli ordinamenti didattici. Studi e Note di Economia 2: 29-61.

BRAUNS, H., GANGL, M., SCHERER, S. (1999). Education and unemployment: patterns of labour market entry in France, the United Kingdom and West Germany. Working paper, No. 6. Mannheim: Mannheimer Zentrum Für Europäische Sozialforschung.

BREIMAN, L., FRIEDMAN, J.H., OLSHEN, R.A., STONE, C.I. (1984). Classification and Regression Trees. Belmont, CA: Wadsworth. 
BROWN, P., HESKETH, A. (2004). The Mismanagement of Talent: Employability and Jobs in the Knowledge Economy. Oxford: Oxford University Press.

CHIANDOTTO, B., BERTACCINI, B. (2003). Profili e sbocchi occupazionali dei laureati e diplomati dell'Ateneo Fiorentino 1999. Firenze: Gruppo VALMON-Università degli Studi di Firenze.

COUPPIÉ, T., MANSUY, M. (2003). Young people and new entrants in European labour markets: the timing of gradual integration'. In: Muller, W., Gangl, M. (eds.): Transition from Education to Work in Europe. Oxford: Oxford University Press, 63-106.

DACRE POOL, L., SEWELL, P. (2007a). The key to employability. Developing a practical model of graduate employability. Education + Training 49(4): 277-289.

DACRE POOL, L., SEWELL, P. (2007b). A New Practical Model of Graduate Employability. Preston, University of Central Lancashire: Centre for Employability.

EUROSTAT (2003). General indicators on transition from school to work. Statistics in focus, Theme 34/2003. Luxembourg: Eurostat.

FABBRIS, L. (2006). Effectiveness of University Education in Italy. Heidelberg: Physica-Verlag. http://dx.doi.org/10.1007/978-3-7908-1751-5

FORRIER, A., SELS, L. (2003). The concept employability: a complex mosaic. Int. J. Human Resources Development and Management 3(2): 102-124. http://dx.doi.org/10.1504/IJHRDM.2003.002414

GARROUSTE, C.L., LOI, M. (2011). School-to-work transitions in Europe: Paths towards a permanent contract. JRC Scientific and Technical Reports, No. 67563: Luxembourg: Publications Office of the European Union, 1-52.

HARTIGAN, J.A. (1975). Clustering Algorithms. New York: John Wiley.

HILLAGE, J., POLLARD, E. (1998). Employability: developing a framework for policy analysis. Research report, No. RR85. London: Department for Education and Employment.

HIND, D., MOSS, S. (2011). Employability Skills. 2nd Ed. Sunderland: Business Education Publishers.

HOARE, R. (2004). Using CHAID for Classification Problems. In: New Zealand Statistical Association 2004 Conference. Wellington: Victoria University.

KASS, G.V. (1980). An exploratory technique for investigating large quantities of categorical data. Applied Statistics 29(2): 119-127.

http://dx.doi.org/10.2307/2986296
LUZZATTO, G., MANGANO, S., MOSCATI, R., PIERI, M.T. (2012). Employability and competences of university graduates in Italy. In: DEHEMS - Employability of Graduates \& Higher Education Management Systems conference proceedings. Ljubljana: University of Ljubljana, 73-87.

MAGIDSON, J. (1994). The CHAID approach to segmentation modeling: Chi-squared automatic interaction detection. In: Bagozzi, R.P. (eds.): In advanced methods of marketing research. Cambridge, MA: Blackwell, 118-159.

MORGAN, J.N., MESSENGER, R.C. (1973). THAID: A sequential analysis program for the analysis of nominal scale dependent variables. Technical report. Ann Arbor: University of Michigan.

QUINTINI, G., MARTIN, J.P., MARTIN, S. (2007). The changing nature of the school-to-work transition process in OECD Countries'. IZA discussion paper, No. 2582. Bonn: IZA.

RATNER, B. (2011). CHAID for interpreting a logistic regression model. In: Ratner, B.: Statistical and Machine-Learning Data Mining. Second Ed. New York: CRC Press, 190-206.

http://dx.doi.org/10.1201/b11508-12

RAMASWAMI, M., BHASKARAN, R. (2010). A CHAID based performance prediction model in educational data mining. International Journal of Computer Science Issues 7(1): 10-18.

RIPLEY, B.D. (1996). Pattern recognition and neural networks. Cambridge: Cambridge University Press.

SCHOMBURG, H., TEICHLER, U. (2006). Higher Education and Graduate Employment in Europe. Results from Graduate Surveys from Twelve Countries. Dordrecht: Springer.

SCHOMBURG, H., TEICHLER, U. (2011). Employability and Mobility of Bachelor Graduates in Europe. Key Results of the Bologna Process. Rotterdam: Sense. http://dx.doi.org/10.1007/978-94-6091-570-3

SPIRO, L.M. (1978). The uses of student market segmentation techniques in college recruitment. Paper presented at the annual Association for Institutional Research Forum (18th, Houston, Texas, May 21-25). Washington: ERIC Clearinghouse (distributed by).

STELLA (2009). Laureati STELLA. Indagine occupazionale post-laurea laureati anno solare 2007. Segrate, Milan: CILEA.

STELLA (2010). Laureati STELLA. Indagine occupazionale post-laurea laureati anno solare 2008. Segrate, Milan: CILEA. 
STELLA (2011). Laureati STELLA. Indagine occupazionale post-laurea laureati anno solare 2009. Segrate, Milan: CILEA.

TEICHLER, U. (2007). Careers of University Graduates. Views and Experiences in Comparative Perspectives. Dordrecht: Springer.

http://dx.doi.org/10.1007/978-1-4020-5926-1

TUKEY, J.W. (1977). The Exploratory Data Analysis. Reading, MA: Addison-Wesley.

WILKINSON, L. (1979). Tests of significance in stepwise regression. Psychological Bulletin 86(1): 168-174. http://dx.doi.org/10.1037/0033$\underline{2909.86 .1 .168}$

WOLBERS, M.H. (2007). Patterns of labour market entry: A comparative perspective in school-to-work transitions in 11 European countries. ActaSociologica, 50(3): 189-210.

\section{Additional sources}

ANTIPOV, E. (2010). Applying CHAID for logistic regression diagnostic and Classification accuracy improvement. Munich Personal RePEc Archive. MPRA Paper, No. 21499. Available at: $<$ http://mpra.ub.uni-muenchen.de/21499/1/MPRA_ paper_21499.pdf>.

BOLOGNA PROCESS (2009). Information about the Bologna process are available online at: $<\mathrm{http}$ ://www.ond.vlaanderen.be/hogeronderwijs/bolog na/about/index.htm>.

CILEA Interuniversity Consortium. Web site: $<$ http://www.cilea.it/1/>.

EUROPEAN COMMISSION (2003). The European Union labour force survey - Methods and definitions 2001. Available at: <http://epp.eurostat.ec.europa.eu/ cache/ITY_OFFPUB/KS-BF-03-002/EN/KS-BF-03002-EN.PDF>.

EUROSTAT website. Labour Force definition: $<$ http://epp.eurostat.ec.europa.eu/portal/page/portal/ employment_unemployment_lfs/methodology/ definitions $>$.

KUSAKCI, S. (2010). Segmentation of student market: A CHAID-based analysis. In: Proceedings of the $6^{\text {th }}$ International Student Conference, Izmir, Turkey. Available at: <http://iibf.ieu.edu.tr/ stuconference/wp-content/uploads/segmentation-of-studentmarket-a-chaid-based-analysis.pdf>.

MINISTERIAL DECREE No. 509 of November the 3rd, 1999. English version: <http://www.crui.it/crui/ ECTS/english/doc\%20En/legislation.pdf>.
OFFICE FOR OFFICIAL PUBLICATIONS OF THE EUROPEAN COMMUNITIES (2004). European credit transfer and accumulation system (ECTS). European Communities. Available at: $<$ http://ec.europa.eu/dgs/education_culture/publ/pdf/ec ts/en.pdfs. 
